\title{
Article
}

\section{Toward a theory-led metaframework for considering socioeconomic health inequalities within systematic reviews}

Maden, Michelle, Mcmahon, Naoimh, Booth, Andrew, Dickson, Rumona, Paisley, Suzy and Gabbay, Mark

Available at http://clok.uclan.ac.uk/24618/

Maden, Michelle, Mcmahon, Naoimh ORCID: 0000-0001-6319-2263, Booth, Andrew, Dickson, Rumona, Paisley, Suzy and Gabbay, Mark (2018) Toward a theory-led metaframework for considering socioeconomic health inequalities within systematic reviews. Journal of Clinical Epidemiology, 104 . pp. 84-94. ISSN 0895-4356

It is advisable to refer to the publisher's version if you intend to cite from the work. http://dx.doi.org/10.1016/j.jclinepi.2018.08.008

For more information about UCLan's research in this area go to

http://www.uclan.ac.uk/researchgroups/ and search for <name of research Group>.

For information about Research generally at UCLan please go to http://www.uclan.ac.uk/research/

All outputs in CLoK are protected by Intellectual Property Rights law, including Copyright law. Copyright, IPR and Moral Rights for the works on this site are retained by the individual authors and/or other copyright owners. Terms and conditions for use of this material are defined in the policies page. 


\section{Accepted Manuscript}

Towards a theory-led meta-framework for considering socioeconomic health inequalities within systematic reviews

Michelle Maden, NIHR NWC CLAHRC PhD, Student, Naoimh McMahon, NIHR NWC CLAHRC PhD, Student, Dr Andrew Booth, BA MSc Dip Lib PhD MCLIP, Rumona Dickson, Professor, Dr Suzy Paisley, Mark Gabbay, MD FRCGP M.B, Professor

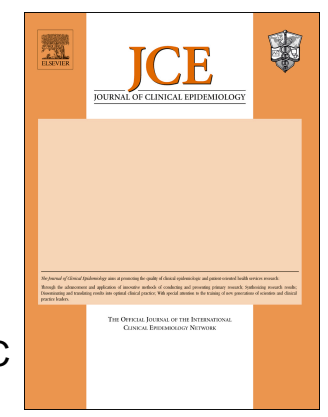

PII: S0895-4356(18)30168-9

DOI: 10.1016/j.jclinepi.2018.08.008

Reference: JCE 9717

To appear in: Journal of Clinical Epidemiology

Received Date: 24 February 2018

Revised Date: 8 July 2018

Accepted Date: 12 August 2018

Please cite this article as: Maden M, McMahon N, Booth A, Dickson R, Paisley S, Gabbay M, Towards a theory-led meta-framework for considering socioeconomic health inequalities within systematic reviews, Journal of Clinical Epidemiology (2018), doi: 10.1016/j.jclinepi.2018.08.008.

This is a PDF file of an unedited manuscript that has been accepted for publication. As a service to our customers we are providing this early version of the manuscript. The manuscript will undergo copyediting, typesetting, and review of the resulting proof before it is published in its final form. Please note that during the production process errors may be discovered which could affect the content, and all legal disclaimers that apply to the journal pertain. 
Title: Towards a theory-led meta-framework for considering socioeconomic health inequalities

\section{Author information}

5 Corresponding author: Michelle Maden, NIHR NWC CLAHRC PhD Student, Department of Health

6 Services Research, University of Liverpool, Liverpool Reviews and Implementation Group (LRIG),

7 Second Floor, Whelan Building, The Quadrangle, Brownlow Hill, Liverpool, L69 3GB. Email:

$8 \quad$ Michelle.Maden@liverpool.ac.uk

Naoimh McMahon, NIHR NWC CLAHRC PhD Student, Faculty of Health and Wellbeing, Brook Building, University of Central Lancashire, Preston, PR1 2HE. Email: NMcMahon@uclan.ac.uk

Dr Andrew Booth, BA MSc Dip Lib PhD MCLIP, Reader in Evidence Based Information Practice, School of Health and Related Research (ScHARR), University of Sheffield, Regent Court, 30 Regent Street,

\section{Sheffield, S1 4DA. Email: A.Booth@sheffield.ac.uk}

Professor Rumona Dickson, Director, Liverpool Reviews and Implementation Group (LRIG), Second Floor, Whelan Building, The Quadrangle, Brownlow Hill, Liverpool, L69 3GB. Email:

rdickson@liverpool.ac.uk

Dr Suzy Paisley, Director of Innovation and Knowledge Transfer (IKT), Senior Research Fellow, ScHARR, University of Sheffield. Email: $\underline{\text { s.paisley@sheffield.ac.uk }}$

Professor Mark Gabbay, MD FRCGP, Professor of General Practice, Director NIHR CLAHRC NWC, University of Liverpool, Block B Waterhouse Building, 1-5 Brownlow St., Liverpool, L69 3GL. Email: M.B.Gabbay@liverpool.ac.uk 


\section{Abstract}

Objective: To develop a theory-led framework to inform reviewers' understanding of what, how and why healthcare interventions may lead to differential effects across socio-economic groups.

Study Design and Setting: A meta-framework approach combined two theoretical perspectives (socio-economic health inequalities and complex interventions) into a single framework to inform socio-economic health inequality considerations in systematic reviews.

Results: Four theories relating to complexity within systematic reviews and 16 health inequalities intervention theories informed the development of a meta-framework. Factors relating to the type of intervention, implementation, context, participant response and mechanisms associated with differential effects across socio-economic groups were identified. The meta-framework can inform; reviewer discussions around how socio-economic status can moderate intervention effectiveness during question formulation, approaches to data extraction and help identify a priori analysis considerations.

Conclusion: The meta-framework offers a transparent, practical, theory-led approach to inform a programme theory for what, how and why interventions work for different socio-economic status groups in systematic reviews. It can enhance existing guidance on conducting systematic reviews that consider health inequalities, increase awareness of how socio-economic status can moderate intervention effectiveness and encourage a greater engagement with theory throughout the review process.

Keywords: Systematic Review, Equity, Methodology, Framework, Programme Theory Running Title: Meta-framework for socioeconomic health inequality considerations in systematic reviews.

Word count (excluding title, abstract, tables, figures, references): 3391 


\section{What is New?}

\section{Key Findings}

A meta-framework was developed to help reviewers formulate an a priori understanding of the potential for their review findings to be moderated by socio-economic status.

\section{What this adds to what is known}

The meta-framework enhances existing guidance on conducting systematic reviews that consider health inequalities by offering reviewers practical guidance in identifying factors and mechanisms associated with differential effects of healthcare interventions across socio-economic groups.

What is the implication, what should change now

Use of the meta-framework promotes an explicit, practical, theory-led approach to inform a programme theory for if, what and how interventions work for different socio-economic status groups. 


\section{Introduction}

Interventions which may be effective in improving the overall health of a population, may inadvertently increase health inequalities(1-4)(i.e. differences in health status between individuals or populations which are avoidable and unjust(5)). White et al.,(1, p.68) label these as 'intervention generated inequalities' (IGIs) i.e., "all processes in the planning and delivery of an intervention have the potential to widen inequalities within the target population, distinguished by a range of factors, such as gender, age, ethnicity or SEP [socio-economic position]". Such IGIs occur for example, when an intervention improves the health of higher socio-economic status (SES) groups at a faster rate than in lower SES groups (i.e. higher SES groups will benefit first, then lower SES groups will catch up)(1, 2).

All healthcare interventions have the potential to impact on health inequalities. The net impact of an intervention may be positive, negative, or have no discernible impact (see figure 1). Such an impact may be the result of either intended, or unintended effects(1). It is imperative therefore, that all reviews consider whether it is likely that their review findings have the potential to impact on health inequalities $(1,3,6)$.

\section{INSERT FIGURE 1}

Guidance on conducting systematic reviews that consider health inequalities encourages reviewers to develop an understanding, or 'programme theory'/logic model, from the outset of their review, of what works, for disadvantaged populations, under what circumstance(7-10). However, much of the guidance assumes that reviewers can recognise a priori, what, how and why interventions_may result in differential effects across different SES populations(11). Consequently, within the review guidance there is a lack of detail on the specific factors and mechanisms (i.e. responses and changes in an 
Table 1: Guidance on conducting systematic reviews incorporating health inequalities.

\begin{tabular}{|l|l|}
\hline Guidance & Guidance item \\
\hline $\begin{array}{l}\text { PRISMA-Equity 2012 } \\
\text { Extension(8) }\end{array}$ & $\begin{array}{l}\text { Rationale 3: "Describe assumptions about mechanism(s) by which the } \\
\text { intervention is assumed to have an impact on health equity." }\end{array}$ \\
\hline $\begin{array}{l}\text { PRISMA-Equity 2012 } \\
\text { Extension(8) }\end{array}$ & $\begin{array}{l}\text { Rationale 3A: "Provide the logic model/analytical framework, if done, to } \\
\text { show the pathways through which the intervention is assumed to affect } \\
\text { health equity and how it was developed." }\end{array}$ \\
\hline $\begin{array}{l}\text { Health equity } \\
\text { plausibility } \\
\text { algorithm(12, 'Table } \\
\text { 1') }\end{array}$ & $\begin{array}{l}\text { "Are there differences in patient/community/ population characteristics } \\
\text { (e.g. underlying pathophysiology, comorbidities, patient attitudes, etc.) } \\
\text { that are likely to create important differences in the magnitude of relative } \\
\text { effect of the intervention versus the control for the outcome of interest?" }\end{array}$ \\
\hline $\begin{array}{l}\text { Health Inequalities } \\
\text { Assessment Toolkit } \\
\text { (HIAT) (10) }\end{array}$ & $\begin{array}{l}\text { "How could the socio-economic circumstances in which your target group } \\
\text { live and work limit their ability to benefit from, or take part in, your } \\
\text { activities? Are there any risks that your work may unintentionally increase } \\
\text { inequalities in health? How would you reduce these risks?" }\end{array}$ \\
\hline
\end{tabular}

Furthermore, in explaining the low reliability of a plausibility algorithm designed to predict relative differences in effectiveness of interventions across SES populations, Welch et al.,(12, 'Discussion') suggest that it "may be due to multi-component questions covering several factors, and potential confusion of access to health care, prognostic factors and treatment-covariate interactions.". This suggests that reviewers need to recognise firstly, what factors relating to an intervention pathway (e.g. the intervention, participant characteristics and access) may moderate intervention different SES groups.

Empirical evidence however, suggests that reviewers struggle to understand how interventions under review may impact on health inequalities(12-15). If reviewers are not able to recognise such issues, then they may be less likely to incorporate health inequality considerations in systematic 
reviews(11). Thus, a framework that offers the potential to facilitate the identification of factors and mechanisms associated with what, how and why interventions may work across different SES groups, may help reviewers to operationalise the guidance on conducting systematic reviews that consider health inequalities.

Such a framework also has the potential to help reviewers identify the types of data to extract, inform a priori analysis of which factors are associated with differential effects and identify possible explanatory factors(i.e. mechanisms) for why some interventions may widen, narrow or have no impact on the health inequality gap. Furthermore, when evidence is lacking from primary research of an impact on socio-economic health inequalities, the framework could provide a structure within which to hypothesise both the likely applicability of review findings and the potential for an intervention to indirectly widen or narrow socio-economic health inequalities.

Given the lack of evaluation of differential effects of interventions across disadvantaged populations, Whitehead $(5, p .477)$ states that it is "imperative to adopt a theory based approach to guide the development and implementation of actions aimed at tackling social inequalities in health.". Several theories and frameworks exist to help reviewers hypothesise how interventions may or may not work across socio-economic groups, but few distinguish between the factors associated with the intervention pathway that may result in differential effectiveness. However, theories relating to complexity in systematic reviews of complex interventions can help reviewers to identify such factors. For example Rohwer et al.,(16) highlight factors relating to participants, intervention design, context and implementation that reviewers should consider when hypothesising how an intervention may or may not work.

Therefore, in considering two theoretical perspectives i.e. health inequality interventions and complexity in systematic reviews of complex interventions within a single framework, we aim to map out the factors and mechanisms associated with the intervention pathway that may lead to differential effects across socio-economic groups. In combining multiple theories into a single 
framework, we adopted a meta-framework approach. This approach identifies both common and unique elements from across multiple theories to inform a single meta-framework $(17,18)$. The objectives are to; i)identify existing theories, guidance and frameworks that consider what, how and why healthcare interventions may lead to differential effects across socio-economic groups, ii)consider the strengths and limitations of these theories iii)identify key factors and mechanisms within the theoretical literature associated with what, why and how interventions may result in differential effects across SES groups and iv)develop a theory-led meta-framework to inform reviewers' understanding of what, how and why healthcare interventions may lead to differential effects across socio-economic groups inform considerations of socio-economic health inequalities in systematic reviews.

\section{Methods}

We adhered to the best-fit framework synthesis guidance on developing a meta-framework $(17,18)$.

This guidance was selected as it offers a theory-led, systematic approach to meta-framework development to help reviewers generate programme theories and test them in systematic reviews. A meta-framework is generated by firstly identifying relevant theories from the published literature. Common and unique themes contributed by each theory are identified and 'deconsituted' into a single meta-framework(18).

We sought theories (the term theory is used here to collectively refer to published theories, frameworks, models and guidance documents) relating to complexity in systematic reviews of complex interventions and health inequality intervention theories about how socio-economic status 
may influence the effectiveness of an intervention. Systematic searches were undertaken in eight resources following guidance on searching for theory(18)(see table 2 and Appendix A). Theories were also identified opportunistically from within relevant theoretical papers, an earlier published work on the use of programme theory in SES focused systematic reviews(11) and informal discussions with health inequality experts. We excluded theories on the causes and determinants of inequalities since they do not focus on interventions.

\section{Table 2: Resources used to identify relevant theories}

MEDLINE, CINAHL, The Cochrane Library (CDSR, Other reviews, HTA), the Database of Promoting Health Effectiveness Reviews (DoPHER), the Campbell Collaboration Library of Systematic Reviews, 3ie (International Initiative for Impact Evaluation) database of systematic reviews, Google Scholar, Campbell and Cochrane Equity Methods Group website, contact with equity experts

A novel two stage approach was adopted in generating the meta-framework. In the first stage we undertook thematic analysis of theories related to complexity in systematic reviews of complex interventions, in order to identify common and unique factors of the intervention pathway that may result in differential effects. These factors provided the scaffold for the meta-framework. In the second stage we analysed health inequality intervention theories to verify which of these factors were also associated with differential effects across SES groups. New factors identified from health inequality intervention theories were incorporated into the meta-framework. Health inequality intervention theories also identified how and why differential effects may arise across SES groups. One author(MM) extracted and coded the data. A second author(NM) checked the data extraction and codes. Disagreement in the coding process were resolved through discussion. 


\section{Results}

Twenty theories (reported in 24 publications) informed the development of the meta-framework.

Four theories (reported in five publications) relate to complexity within systematic reviews of complex interventions $(16,19-22)$ and 16 (reported in 19 publications) $(1,3-5,10,12,23-35)$ relate to health inequality intervention theories. The strengths and weaknesses of the theories informing the meta-framework are summarised in Appendix B. When considered together, theories relating to complex interventions and socio-economic health inequalities can help to inform reviewers' understanding of what, why and how factors associated with the intervention pathway may result in differential effectiveness across SES groups (see figure 2 and Appendix C). Appendix D outlines the contribution of each of the theories to the meta-framework.

INSERT FIGURE 2

\section{1 'What' factors may be associated with differential effects of healthcare interventions across} socio-economic groups

\subsubsection{Factors associated with differential effectiveness across complex interventions}

Theories relating to complexity in systematic reviews of complex interventions identify four key factors of the intervention pathway associated with differential effects; intervention, implementation, context, participant response. Specific factors relating to intervention, implementation, context and participant response were also identified (see figure 2 and appendix $D(D 1))$.

\subsubsection{Factors associated with differential effectiveness across socio-economic groups}

All factors identified in theories of complexity in systematic reviews as having the potential to result in differential effects across SES groups were verified in the health inequality intervention theories. 
Health inequality intervention theories also identify additional specific intervention,

implementation, context, and participant response factors associated with differential effects across SES groups (see figure 2 and appendix D(D2-D5)).

\subsubsection{Intervention factors associated with differential effectiveness across SES groups}

All 16 socio-economic theories describe intervention factors which may be associated with

differential effects across SES groups (see figure 2 and appendix D(D2)). In particular, they categorise

factors relating to types of intervention components and identify six additional intervention factors intervention', and are supported by a single socio-economic health inequalities theory, other factors are supported by two or more theories.

\subsubsection{Implementation factors associated with differential effectiveness across SES groups}

Fifteen socio-economic health inequality theories highlight implementation factors associated with differential effectiveness across SES groups (see figure 2 and appendix $D(D 3)$ ). These theories identify three additional implementation factors relating to delivery mechanisms as being associated with differential effectiveness across SES; resources (infrastructure, manpower), cost (cost to recipient, cost to provider) and mode of delivery (face-to-face, media). The majority of factors are supported by three or more theories. 
206

207

208

209

210

211

212

213

214

215

216

217

218

219

220

221

222

223

226

227

228

229

230

All socio-economic health inequalities theories identify context factors associated with differential effectiveness across SES groups (see figure 2 and appendix D(D4)). All theories identify factors relating to personal context (i.e. individual socio-demographic characteristics). Twelve socioeconomic health inequality theories identify factors relating to the wider environmental context (i.e. factors outside the control of an individual, e.g. laws, cultural beliefs). One health inequality framework, PROGRESS-plus(4), categorises factors relating to personal context. PROGRESS-plus identifies additional personal context factors not previously identified in the complexity theories. All context factors are supported by two or more socio-economic health inequality theories.

\subsubsection{Participant response factors associated with differential effectiveness across SES groups}

Fifteen socio-economic health inequality theories identify participant response factors associated with differential effectiveness across SES groups (see figure 2 and appendix $D(D 5)$ ). The majority of socio-economic health inequality theories identify behavioural responses (e.g. adherence or motivation). All participant response factors are supported by four or more socio-economic health inequality theories.

\section{2 'How' factors may be associated with differential effects of healthcare interventions across} socio-economic groups?

Socio-economic health inequality theories suggest that differential effects across SES groups may occur during either the provision of, or response to an intervention (e.g. see $(1,3,30)$. The key stages at which they may be introduced relate to, effectiveness (relative and absolute effectiveness), costeffectiveness and access to an intervention (see figure 2 and appendix $D(D 6)$ ). Furthermore, differential effects may be exacerbated because of cumulative effects experienced $(1,3,24,26,30$, 35). In other words, if lower SES groups experience worse outcomes at each stage at which inequalities can arise compared to higher SES groups, then a greater overall reduction in effectiveness is likely for lower SES groups. 
Differential effects in health outcomes may arise due to differences in absolute or relative

232

233

234

effectiveness. Differences in absolute effects are mediated by differences in the baseline risk of outcomes in populations(12). For example, even if a new intervention is equally efficacious for both lower and higher SES groups, if lower SES groups have a higher baseline risk of mortality then the absolute difference in effectiveness will be greater for lower SES groups(3, 12, 25).

Differences in relative effects may arise due to differences in mechanisms of action and may be moderated by differences in recipient characteristics, the way in which an intervention is designed or implemented, or wider contextual influences $(1,30)$. For example, a greater relative reduction in obesity may be seen in higher SES groups than lower SES groups if lower SES groups are unable to afford healthier food options, or are exposed to unhealthier environments.

Differences in relative effects are also influenced by levels of access to an intervention. Based on a synthesis of the literature on the conceptualisation of access, Levesque et al.'s(33) framework offers the most comprehensive definition of access (see table 3). They describe how differences in levels of access are mediated by differences in approachability, acceptability, availability and accommodation, affordability and appropriateness. In addition, if interventions which are successful in reducing socio-economic health inequalities are not cost-effective, then they may not be implemented. However, if people value the reduction in inequalities, the benefit/cost ratio could be shifted.

Table 3: Defining access (Levesque et al. (33, 'A definition of access as an opportunity', 'Five dimensions of access capturing supply-side and demand-side determinants'))

Access: "the possibility to identify healthcare needs, to seek healthcare services, to reach healthcare services, to reach the healthcare resources, to obtain or use health care services, and to actually be offered services appropriate to the needs for care."

Approachability: "people facing health needs can actually identify that some form of service exists, can be reached and have an impact on the health of the individual" 
Acceptability: "cultural and social factors determining the possibility for people to accept the aspects of the service (e.g. the sex or social group of providers, the beliefs associated to systems of medicine) and the judged appropriateness for the persons to seek care."

Availability and accommodation: "health services (either the physical space or those working in health care roles) can be reached both physically and in a timely manner."

Affordability: "the economic capacity for people to spend resources and time to use appropriate services."

Appropriateness: "the fit between services and clients need, its timeliness, the amount of care spent in assessing health problems and determining the correct treatment and the technical and interpersonal quality of the services provided".

Lower levels of access and/or effectiveness among lower socio-economic groups may lead to a widening of health inequalities and have a negative impact on the health inequalities gap. Higher levels of access and/or effectiveness among lower socio-economic groups may lead to a narrowing of health inequalities and have a positive impact on the health inequalities gap. Equivalent levels or an overall balancing out of access and/or effectiveness between socio-economic groups may maintain existing health inequalities and have no impact on the health inequalities gap.

3.3 'Why' factors may be associated with differential effects of healthcare interventions across socio-economic groups

Socio-economic health inequality theories identify seven key mechanisms that may help to explain not described as an explicit part of a testable framework. 


\begin{tabular}{|c|c|c|c|}
\hline \multirow[t]{2}{*}{ Mechanisms } & \multirow[t]{2}{*}{ Definition } & \multicolumn{2}{|l|}{ Examples $^{2}$} \\
\hline & & $\begin{array}{l}\text { Potential for a positive impact on } \\
\text { socio-economic health } \\
\text { inequalities }\end{array}$ & $\begin{array}{l}\text { Potential for a negative impact } \\
\text { on socio-economic health } \\
\text { inequalities }\end{array}$ \\
\hline \multicolumn{4}{|l|}{ 1. Choice } \\
\hline $\begin{array}{l}1.1 \text { Ability to } \\
\text { choose }\end{array}$ & $\begin{array}{l}\text { The ability to have a free choice in } \\
\text { providing or receiving healthcare. } \\
\text { Relates to an individual's life } \\
\text { circumstances (e.g. religious or } \\
\text { cultural beliefs, socio-economic } \\
\text { status, vulnerable groups) or wider } \\
\text { environmental factors (e.g. ethics, } \\
\text { legal rights, political) that may } \\
\text { influence the ability to choose. }\end{array}$ & $\begin{array}{l}\text { "Low-income parents often } \\
\text { struggle to afford the fruit and } \\
\text { vegetables they know to be } \\
\text { important for their children's } \\
\text { health [23]. Using subsidies to } \\
\text { make healthier food more } \\
\text { affordable is a low-agency } \\
\text { population intervention that may } \\
\text { increase the choices available to } \\
\text { these parents."(35) }\end{array}$ & $\begin{array}{l}\text { "A common attribute of } \\
\text { interventions that lead to } \\
\text { increase socioeconomic } \\
\text { inequalities in health appears to } \\
\text { be a reliance on voluntary } \\
\text { behaviour change (Mechanic, } \\
\text { 2002)."(1) }\end{array}$ \\
\hline \multicolumn{4}{|l|}{ 2. Effectiveness } \\
\hline $\begin{array}{l}2.2 \text { Ability to } \\
\text { control }\end{array}$ & $\begin{array}{l}\text { The ability to control behaviour or } \\
\text { actions. Relates to an individual's } \\
\text { life circumstances (e.g. risk of } \\
\text { disease, epidemiological } \\
\text { characteristics) or wider } \\
\text { environmental factors (e.g. } \\
\text { exposure to harmful environments) } \\
\text { that may influence the ability to } \\
\text { control. Corresponds to 'Exposure'. }\end{array}$ & $\begin{array}{l}\text { "The relative efficacy of treated } \\
\text { bed nets on childhood mortality } \\
\text { is unlikely to differ across } \\
\text { socioeconomic status since the } \\
\text { risk of malaria is similar across } \\
\text { socioeconomic gradients in areas } \\
\text { of comparable endemicity. } \\
\text { However, the absolute difference } \\
\text { may be greater in the poorest } \\
\text { people, who start with higher } \\
\text { baseline mortality(359)."(3) }\end{array}$ & $\begin{array}{l}\text { "Person" interventions appeared } \\
\text { most likely to widen inequalities. } \\
\text { This category included health } \\
\text { education and dietary } \\
\text { counselling. This may reflect the } \\
\text { dependence on an individual } \\
\text { choosing to behave differently, } \\
\text { and sustain that change [78]. } \\
\text { Other studies support this in } \\
\text { highlighting that downstream } \\
\text { interventions rarely reduce } \\
\text { inequalities and may widen } \\
\text { them."(34) }\end{array}$ \\
\hline \multicolumn{4}{|l|}{ 3. Access } \\
\hline $\begin{array}{l}\text { 3.1 Ability to } \\
\text { perceive }\end{array}$ & $\begin{array}{l}\text { The ability to recognise a need for } \\
\text { healthcare. Relates to knowledge, } \\
\text { beliefs and understanding of health } \\
\text { risks and awareness of the benefits } \\
\text { of interventions designed to } \\
\text { improve health. Corresponds to the } \\
\text { dimension of access } \\
\text { 'Approachability'. }\end{array}$ & $\begin{array}{l}\text { "As a result of these discussions } \\
\text { the team revised their planned } \\
\text { intervention to address these } \\
\text { socio-economic barriers by: (i) } \\
\text { including initial preliminary } \\
\text { research to identify people's } \\
\text { perception of health checks and } \\
\text { how they could be redesigned in } \\
\text { order to optimise people's needs } \\
\text { and restrictions;...and; (iii) } \\
\text { extending staff training to } \\
\text { increase awareness of the social } \\
\text { determinants of health } \\
\text { inequalities in general and the } \\
\text { socio-economic barriers to } \\
\text { uptake of preventive services in } \\
\text { particular."(10) }\end{array}$ & $\begin{array}{l}\text { "In India, for example, } 30 \% \text { of } \\
\text { mothers of children who had not } \\
\text { been vaccinated did not know } \\
\text { that immunisation was important } \\
\text { for the health of their child, and a } \\
\text { further } 33 \% \text { did not know where } \\
\text { to go to have their child } \\
\text { vaccinated."(26) }\end{array}$ \\
\hline $\begin{array}{l}3.2 \text { Ability to } \\
\text { seek }\end{array}$ & $\begin{array}{l}\text { The ability to have the personal } \\
\text { autonomy and capacity to seek } \\
\text { health care. Corresponds to the } \\
\text { dimension of access } \\
\text { 'Acceptability'. }\end{array}$ & $\begin{array}{l}\text { "Increasing the number of female } \\
\text { doctors can improve access to } \\
\text { health care for women from } \\
\text { Arabic-speaking countries living } \\
\text { in Sweden[63]."(4) }\end{array}$ & $\begin{array}{l}\text { "The way health checks are } \\
\text { delivered, in terms of form and } \\
\text { content and the people } \\
\text { delivering them (in terms of } \\
\text { professional, ethnic and gender } \\
\text { background) can put people off } \\
\text { from attending."(10) }\end{array}$ \\
\hline $\begin{array}{l}\text { 3.3 Ability to } \\
\text { reach }\end{array}$ & $\begin{array}{l}\text { The ability to mobilise and the } \\
\text { availability of transportation, } \\
\text { occupational flexibility and } \\
\text { knowledge about health services } \\
\text { that allows an individual to reach } \\
\text { an intervention both physically and } \\
\text { in a timely manner. Corresponds to } \\
\text { the dimension of access } \\
\text { 'Availability and accommodation'. }{ }^{1}\end{array}$ & $\begin{array}{l}\text { "Targeting can take several } \\
\text { forms. One -typically called } \\
\text { direct targeting - is to identify } \\
\text { poor households or individuals } \\
\text { and ways of getting services to } \\
\text { them." }(26)\end{array}$ & $\begin{array}{l}\text { "The facilities serving poor } \\
\text { people are typically less well } \\
\text { organised than are those for } \\
\text { people who are better off, with } \\
\text { inconvenient opening hours." }(26)\end{array}$ \\
\hline $\begin{array}{l}3.4 \text { Ability to } \\
\text { pay }\end{array}$ & $\begin{array}{l}\text { The ability to afford healthcare. } \\
\text { Relates to the cost of accessing an } \\
\text { intervention. Cost may be tangible } \\
\text { (e.g. financial) or intangible (e.g. } \\
\text { time). Corresponds to the } \\
\text { dimension of access 'Affordability'. }{ }^{1}\end{array}$ & $\begin{array}{l}\text { "Ownership of malaria bednets } \\
\text { decreases with decreasing } \\
\text { household wealth ... distribution } \\
\text { of free bednets or vouchers for } \\
\text { bednets increases ownership."(4) }\end{array}$ & $\begin{array}{l}\text { "The location and timing of } \\
\text { health checks can have a } \\
\text { negative impact on uptake by } \\
\text { making access difficult, especially } \\
\text { if people cannot access reliable } \\
\text { and affordable public transport }\end{array}$ \\
\hline
\end{tabular}




\begin{tabular}{|c|c|c|c|}
\hline & & & $\begin{array}{l}\text { or cannot negotiate time out } \\
\text { from work or caring } \\
\text { responsibilities."(10) }\end{array}$ \\
\hline $\begin{array}{l}\text { 3.5 Ability to } \\
\text { engage }\end{array}$ & $\begin{array}{l}\text { The ability to participate, interact } \\
\text { with the intervention provided, be } \\
\text { involved in decision-making, have } \\
\text { the capacity to communicate and } \\
\text { to receive appropriate care. } \\
\text { Corresponds to the dimension of } \\
\text { access 'Appropriateness. }{ }^{1}\end{array}$ & $\begin{array}{l}\text { "population interventions that } \\
\text { require recipients to use little or } \\
\text { no agency to benefit may be } \\
\text { more effective and equitable. } \\
\text { When food manufacturers } \\
\text { reduce the salt content of bread, } \\
\text { decreased salt intake occurs } \\
\text { without individuals having to } \\
\text { consciously engage with any } \\
\text { information or actively change } \\
\text { their behaviour [9]."(35) }\end{array}$ & $\begin{array}{l}\text { "More socioeconomically } \\
\text { advantaged people, with better } \\
\text { health literacy (a cognitive } \\
\text { resource.) [17], may find it easier } \\
\text { to make sense of the information } \\
\text { provided in public health } \\
\text { messages."(35) }\end{array}$ \\
\hline
\end{tabular}

${ }^{1}$ as defined by Levesque et al.(33), see table $1 .{ }^{2}$ See appendix D for additional examples.

Appendix $D(D 7)$ highlights the extent to which socio-economic health inequality theories support

the effectiveness mechanism and 10 support the choice mechanism. The way in which intervention, mechanisms resulting in a net positive, negative, or no impact on socio-economic health inequalities.

\section{Discussion}

Multiple theories and frameworks exist to prompt researchers to consider socio-economic health inequalities. To our knowledge, the meta-framework presented above (see figure 2 ) is the first attempt to provide reviewers with practical guidance on identifying factors and mechanisms associated with differential effects across SES groups. To our knowledge, it is also the first time that socio-economic health inequalities have been considered in a meta-framework within the wider context of complex interventions.

Waters et al.(36, p.462) suggest that consideration of the wider context and implementation should be "an essential, non-negotiable component of the review process." None of the theories 
pathway (i.e. intervention, implementation, context, participant response) (see Appendix D).

Furthermore, socio-economic health inequalities theories were found to be less explicit in detailing

implementation, wider environmental context dimensions and mechanisms associated with also decision-makers and practitioners to assess the applicability of, and implement review findings.

Socio-economic theories also suggest that different mechanisms may be more closely related to different socio-economic characteristics than others. For example, the 'ability to perceive' and 'ability to engage' are more likely to be mediated by educational status, whereas 'ability to pay' is more likely to be mediated by income status. This may have implications for reviewers when defining 'socio-economic status'. Consequently, it is anticipated that some factors (e.g. setting, cost to recipient) may exert a stronger influence on differential effectiveness across SES populations than others. Further research is required in identifying which factors related to intervention, implementation, context and participant response are more closely associated with specific mechanisms and the resulting net impact (i.e. positive, negative or no impact) on socio-economic health inequalities.

The key mechanisms identified above are likely to be interdependent to differing extents. For example, Tugwell et al.,(3) suggest that lower SES groups may have greater adherence (ability to engage) in use of bed nets because of their higher exposure to mosquito biting environments (ability to control). In addition, the key mechanisms may be triggered by other mechanisms specific to a particular context. For example, the Health Inequalities Assessment Toolkit(10) suggest that because people of lower SES may work longer hours, under poor working conditions, including job insecurity, 
then they may prioritise (ability to prioritise) providing for their families over attending health checks (ability to seek). The meta-framework identifies mechanisms at a broad level (i.e. not specific to a single intervention) and therefore can act as a prompt to develop and test hypotheses about specific mechanisms and interactions.

One of the key strengths of the meta-framework is its foundation in published theories, frameworks and logic models. In providing a conceptual framework to aid a priori understandings of what interventions may work for different SES groups and why, the meta-framework aims to make the use of theory more accessible to systematic reviewers. It can also act as an evaluation framework to inform a data extraction tool. In this way the meta-framework encourages reviewers to engage with, and build upon theory throughout the review process. Furthermore, in encouraging reviewers to consider context and implementation factors simultaneously with intervention effectiveness, the meta-framework also aims to increase the usefulness of systematic reviews in decision-making and changes to practice (36). Although developed explicitly for systematic reviews, the meta-framework may also be useful in informing socio-economic health inequality considerations in other types of reviews and primary research. Furthermore, whilst the meta-framework acknowledges the moderating effects of other health inequalities as defined in PRORESS-Plus(4) (e.g. gender, ethnicity), the focus here is on the moderating influence of socio-economic status.

The meta-framework is not designed to introduce rigidity into the review process(37). Its value lies in "its ability to allow an acceptable, systematic, tested and refined a posteriori reasoning rather than post hoc assumption of how interventions may work"(11, Discussion). The meta-framework is flexible enough to allow new factors and mechanisms to be incorporated and can be used, for example, to inform data extraction within a best-fit framework synthesis(18). enhances the internal validity of the meta-framework, additional testing and validation of the metaframework is required to ensure it is fit for purpose(18). This will include for example, assessing 
whether additional factors and mechanisms associated with differential effects are identified from theories that meet the inclusion criteria but were not captured by the search. Methodological challenges in identifying and selecting theories, operationalising definitions and evaluating the metaframework are discussed in greater detail elsewhere.(38)

Depending on the review focus, not all parts of the meta-framework will need to be operationalised. Furthermore, it is beyond the scope of this study to explore all potential mechanisms and pathways to effectiveness. It does not attempt to incorporate specific behaviour change theories but recognises that such theories can help inform the interpretation of the meta-framework. Instead, the meta-framework aims to serve as an adaptable, transparent guide to prompt reviewers to consider whether to expect differential effects across SES due to differences in access, clinical effectiveness and cost-effectiveness.

\section{Conclusions}

By offering a systematic approach to the identification of socio-economic theories the metaframework provides a strong theoretical platform with which to consider socio-economic health inequalities in systematic reviews. In providing a transparent, practical approach to using published theories to inform a programme theory for what, how and why interventions work for different SES groups, the meta-framework can enhance existing guidance on conducting systematic reviews that consider health inequalities increase awareness of how SES can moderate intervention effectiveness and encourage a greater engagement with theory throughout the review process.

\section{Abbreviations}

3ie: International Initiative for Impact Evaluation database 
IGI: Intervention generated inequalities

SEP: Socio-economic position

SES: Socio-economic status

Declarations

\section{Acknowledgements}

Thanks to Eleanor Kotas, Information Scientist, Liverpool Reviews and Implementation Group,

University of Liverpool for reviewing the search strategy.

\section{Funding}

MM and NMcM are PhD students funded by The National Institute for Health Research

Collaboration for Leadership in Applied Health Research and Care North West Coast (NIHR CLAHRC NWC). $A B$ is funded by the University of Sheffield to collaborate via the Translating Knowledge into Action (TK2A) theme, NIHR CLAHRC Yorkshire and Humber. MG and RD are part funded by The NIHR CLAHRC NWC.

\section{Contributions to study}

$\mathrm{MM}$ was responsible for the overall design of the study, designed and conducted the search, designed data collection, extracted data, undertook thematic analysis, constructed the framework and wrote the first draft and final draft of this paper. NMcM independently checked the data extraction, thematic analysis and construction of the framework. $A B$ advised on the design and commented on drafts of the study. RD, MG, SP supplemented the methodological and theoretical aspects of the study and provided feedback on drafts of the study. 
Department of Health and Social Care.

1. White M, Adams J, Heywood P. How and why do interventions that increase health overall widen inequalities within populations? In: Babones S, editor. Social Inequality and Public Health. Bristol: Policy Press; 2009. p. 65-83.

2. Lorenc $T$, Petticrew $M$, Welch $V$, Tugwell $P$. What types of interventions generate inequalities? Evidence from systematic reviews. Journal of Epidemiology and Community Health. 2013;67(2):190-3.

400 3. Tugwell P, de Savigny D, Hawker G, Robinson V. Applying clinical epidemiological methods to health equity: the equity effectiveness loop. BMJ. 2006;332(7537):358-61.

4. O'Neill J, Tabish H, Welch V, Petticrew M, Pottie K, Clarke M, et al. Applying an equity lens to interventions: using PROGRESS ensures consideration of socially stratifying factors to illuminate inequities in health. Journal of Clinical Epidemiology. 2014;67(1):56-64.

5. Whitehead M. A typology of actions to tackle social inequalities in health. Journal of Epidemiology and Community Health. 2007;61(6):473-8.

6. Bonnefoy J, Morgan A, Kelly M, Butt J, Bergman V. Constructing the evidence base on the social determinants of health: a guide. Geneva: WHO Measurement and Evidence Knowledge Network; 2007.

7. Tugwell P, Petticrew M, Kristjansson E, Welch V, Ueffing E, Waters E, et al. Assessing equity in systematic reviews: realising the recommendations of the Commission on Social Determinants of Health. BMJ. 2010;341:c4739.

413 8. Welch V, Petticrew M, Tugwell P, Moher D, O'Neill J, Waters E, et al. PRISMA-Equity 2012 extension: reporting guidelines for systematic reviews with a focus on health equity. PLoS Medicine 2012;9(10):e1001333.

416 9. Welch V, Petticrew M, Petkovic J, Moher D, Waters E, White $\mathrm{H}$, et al. Extending the PRISMA 417 statement to equity-focused systematic reviews (PRISMA-E 2012): explanation and elaboration. 418 Journal of Clinical Epidemiology. 2016;70:68-89.

419 10. NIHR CLAHRC North West Coast. Health inequalities assessment toolkit (HIAT). 2017

420 [Available from: http://www.hiat.org.uk/.

421 11. Maden M, Cunliffe A, McMahon N, Booth A, Carey GM, Paisley S, et al. Use of programme theory to understand the differential effects of interventions across socio-economic groups in systematic reviews-a systematic methodology review. Systematic Reviews 2017;6(1):266.

424 12. Welch V, Brand K, Kristjansson E, Smylie J, Wells G, Tugwell P. Systematic reviews need to consider applicability to disadvantaged populations: inter-rater agreement for a health equity plausibility algorithm. BMC Medical Research Methodology. 2012;12:187. 
427 13. Runnels V, Tudiver S, Doull M, Boscoe $M$. The challenges of including sex/gender analysis in 428 systematic reviews: a qualitative survey. Systematic Reviews 2014;3:33.

429 14. Maden M, Dickson R. Health Inequalities and Evidence Synthesis as part of the CLAHRC 430 NWC. Position Statement. Liverpool: Evidence Synthesis Theme, CLARHC NWC, University of 431 Liverpool; 2015.

432 15. Maden M. Consideration of health inequalities in systematic reviews: a mapping review of 433 guidance. Systematic Reviews. 2016;5(1):202.

434 16. Rohwer A, Booth A, Pfadenhauer L, Brereton L, Gerhardus A, Mozygemba K, et al. Guidance on the use of logic models in health technology assessments of complex interventions. 2016.

17. Carroll C, Booth A, Leaviss J, Rick J. "Best fit" framework synthesis: refining the method. BMC Medical Research Methodology. 2013;13:37.

18. Booth A, Carroll C. How to build up the actionable knowledge base: the role of 'best fit' framework synthesis for studies of improvement in healthcare. BMJ quality \& safety. 2015;24(11):700-8.

19. Anderson LM, Petticrew M, Chandler J, Grimshaw J, Tugwell P, O'Neill J, et al. Introducing a series of methodological articles on considering complexity in systematic reviews of interventions. Journal of Clinical Epidemiology. 2013;66(11):1205-8.

20. Lewin S, Hendry M, Chandler J, Oxman AD, Michie S, Shepperd S, et al. Assessing the complexity of interventions within systematic reviews: development, content and use of a new tool (iCAT_SR). BMC Medical Research Methodology. 2017;17(1).

21. Pfadenhauer L, Rohwer A, Burns J, Booth A, Lysdahl K, Hofmann B, et al. Guidance for the Assessment of Context and Implementation in HTA and Systematic Reviews of Complex Interventions.: The Context and Implementation of Complex Interventions (CICI) Framework. 2016. 22. Pigott $\mathrm{T}$, Shepperd S. Identifying, documenting, and examining heterogeneity in systematic reviews of complex interventions. Journal of Clinical Epidemiology. 2013;66(11):1244-50.

23. Hart J. The inverse care law. The Lancet. 1971;1(7696):405-12.

24. Tanahashi T. Health service coverage and its evaluation. Bulletin of the World Health Organization. 1978;56(2):295-303.

25. Victora C, Vaughan J, Barros F, Silva A, Tomasi E. Explaining trends in inequities: evidence from Brazilian child health studies. The Lancet. 2000;356:1093-8.

26. Victora C, Wagstaff A, Armstrong Schellenberg J, Gwatkin D, Claeson M, Habicht J-P. Applying an equity lens to child health and mortality: more of the same is not enough. The Lancet. 2003;362:233-41.

27. Graham H, Kelly M. Health inequalities: concepts, frameworks and policy. In: Agency HD, editor. London2004.

28. Starfield S. What can we learn from equity research and interventions? Australian Journal of Primary Health. 2004;10(3):7-10.

29. Starfield B. Pathways of influence on equity in health. Social Science \& Medicine. 2007;64(7):1355-62.

30. Welch V, Tugwell P, Morris EB. The equity-effectiveness loop as a tool for evaluating population health interventions. Revista de Salud Publica (Bogota, Colombia). 2008;10 Suppl:83-96. 31. Frieden T. A Framework for Public Health Action: The Health Impact Pyramid. American Journal of Public Health. 2010;100:590-5.

32. Braveman P, Kumanyika S, Fielding J, LaVeist T, Borrell L, Manderscheid R, et al. Health Disparities and Health Equity: The Issue Is Justice. American Journal of Public Health. 2011;101:S149-S55.

33. Levesque J, Harris M, Russell G. Patient-centred access to health care: conceptualising access at the interface of health systems and populations. International Journal for Equity in Health. 2013;12:18. 
476 34. McGill R, Anwar E, Orton L, Bromley H, Lloyd-Williams F, O'Flaherty M, et al. Are

477 interventions to promote healthy eating equally effective for all? Systematic review of

478 socioeconomic inequalities in impact. BMC Public Health. 2015;15:457.

479 35. Adams J, Mytton O, White M, Monsivais P. Why Are Some Population Interventions for Diet

480 and Obesity More Equitable and Effective Than Others? The Role of Individual Agency. PLoS

481 Medicine. 2016;13(4):e1001990.

482 36. Waters E, Hall BJ, Armstrong R, Doyle J, Pettman TL, de Silva-Sanigorski A. Essential 483 components of public health evidence reviews: capturing intervention complexity, implementation, economics and equity. Journal of public health (Oxford, England). 2011;33(3):462-5. 37. Kneale D, Thomas J, Harris K. Developing and Optimising the Use of Logic Models in Systematic Reviews: Exploring Practice and Good Practice in the Use of Programme Theory in Reviews. PLoS One. 2015;10(11):e0142187. 38. Maden M, McMahon N, Booth A, Dickson R, Paisley S, Gabbay M. Methodological challenges when developing meta-frameworks in evidence synthesis: A worked example of a socio-economic health inequalities meta-framework. Manuscript in preparation.

491 39. Moore G, Audrey S, Barker M, Bond L, Bonell C, Cooper C, Hardeman W, Moore L, O'Cathain 492 A, Tinati T, Wright D, Baird J. Process evaluation in complex public health intervention studies: the need for guidance. Journal of Epidemiology and Community Health. 2014;68:101-102. 
Difference in intervention effectiveness

between lower socio-economic (SES) and

higher SES groups

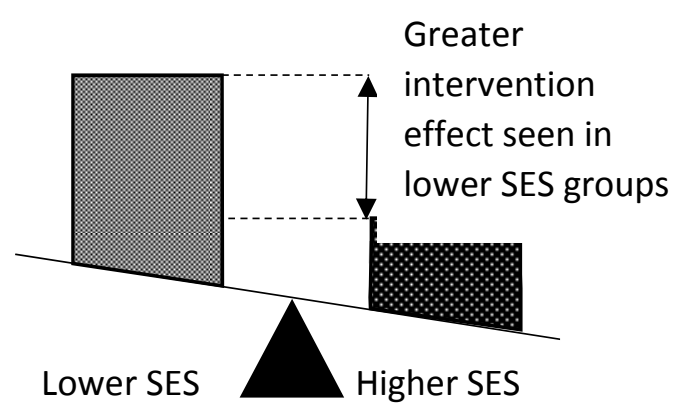

Greater

intervention

effect seen in

higher SES groups
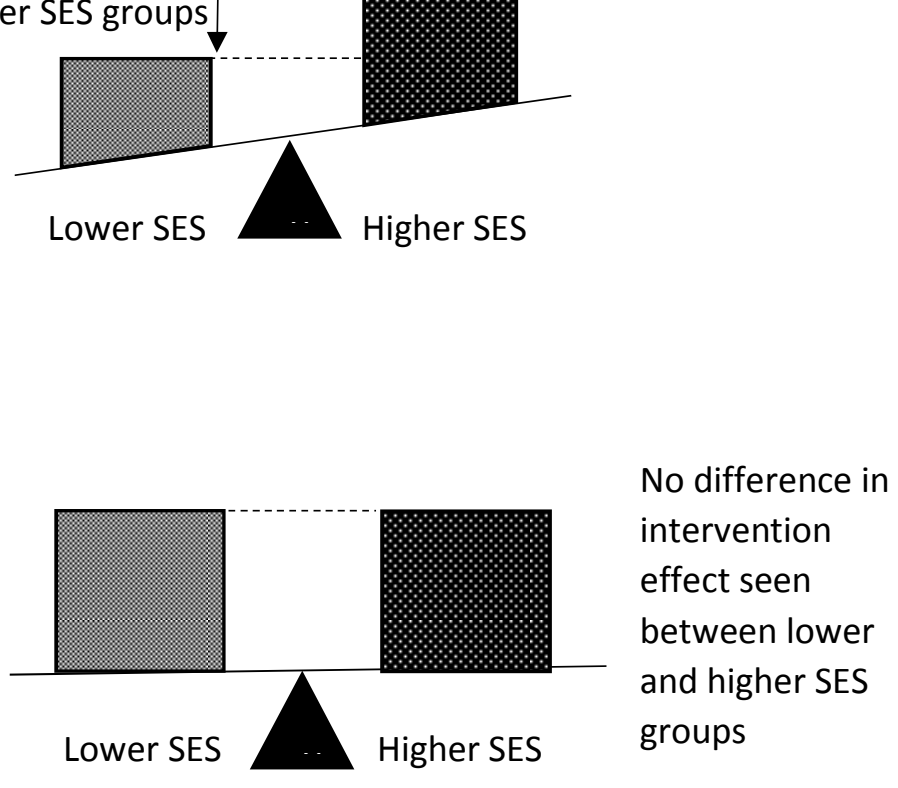

Impact on health inequalities

Figure 1 Potential impact of healthcare interventions on health inequalities

\section{$\underline{\text { Positive net impact }}$}

Intervention likely to reduce inequalities: the intervention preferentially improved the health in people of lower SES.

\section{Negative net impact}

Intervention likely to widen inequalities: the intervention preferentially improved the health in people of higher SES.

\section{No net impact}

Intervention had no preferential impact by SES. 
- Personal (Place of residence, Race/ethnicity/culture, Occupation, Gender, Religion, Education, Income, Social Capital, Age, Disability, Sexual Orientation)

- Environmental (Geographical, Epidemiological, Socio-cultural, Socio-economic, Ethical, Legal, Political, Policy, Financing, Organisation \& Structure) ${ }^{2}$

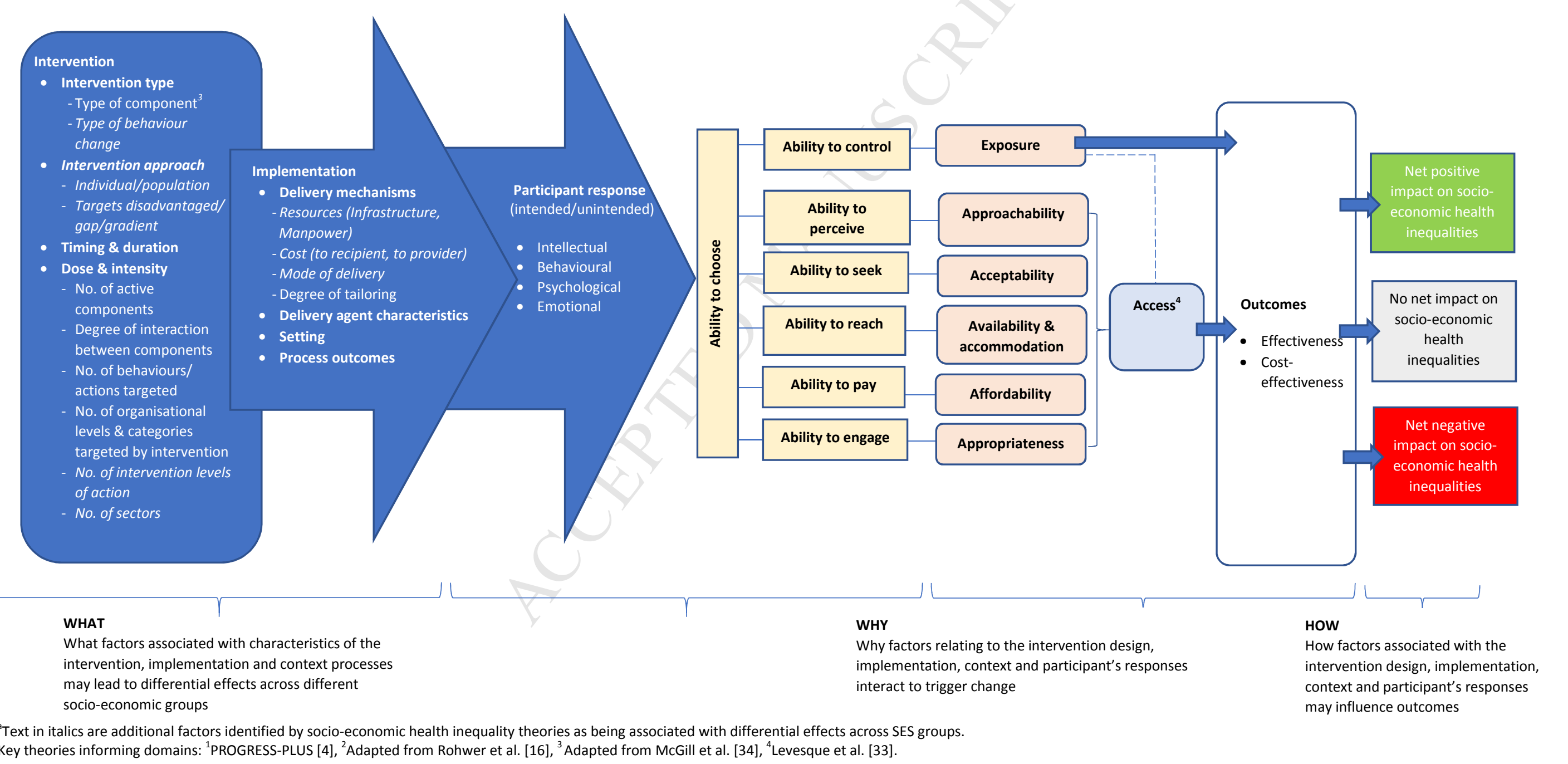

